\title{
New therapeutic targets in the management of urothelial carcinoma of the bladder
}

This article was published in the following Dove Press journal:

Research and Reports in Urology

28 February 2013

Number of times this article has been viewed

\section{Einar F Sverrisson \\ Patrick N Espiritu \\ Philippe E Spiess}

Department of Genitourinary Oncology, H Lee Moffitt Cancer Center, Tampa, FL, USA

Video abstract

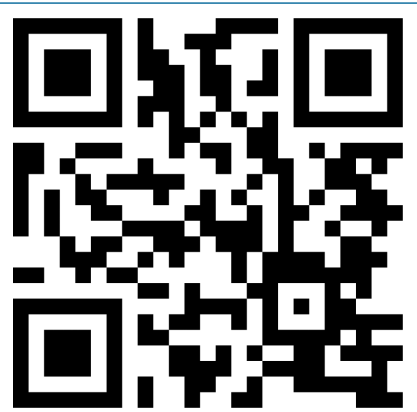

Point your SmartPhone at the code above. If you have a QR code reader the video abstract will appear. Or use: http://dvpr.es $/ X_{j} d 40 \mathrm{~g}$

Correspondence: Philippe E Spiess Moffitt Cancer Center, 12902

Magnolia Drive Office 12538 ,

Tampa, FL 336 I 2, USA

Tel +l 8137458343

Fax + I 8I3 7458494

Email philippe.spiess@moffitt.org
Abstract: Urothelial carcinoma of the bladder, despite the myriad of treatment approaches and our progressively increasing knowledge into its disease processes, remains one of the most clinically challenging problems in modern urological clinical practice. New therapies target biomolecular pathways and cellular mediators responsible for regulating cell growth and metabolism, both of which are frequently overexpressed in malignant urothelial cells, with the intent of inducing cell death by limiting cellular metabolism and growth, creating an immune response, or selectively delivering or activating a cytotoxic agent. These new and novel therapies may offer a potential for reduced toxicity and an encouraging hope for better treatment outcomes, particularly for a disease often refractory or not amenable to the current therapeutic approaches.

Keywords: targeted therapy, intravesical agents, systemic therapies

\section{Introduction to the management issues - current and emerging treatment options}

Urothelial carcinoma (UC) of the bladder (UCB) is the ninth most common cancer worldwide, affecting approximately four times more men than women, with a global mortality rate of 4 per 100,000 amongst men, compared with 1.1 per 100,000 amongst women. ${ }^{1}$ Approximately $70 \%$ of newly diagnosed patients have non-muscle-invasive tumors. Recurrence of non-muscle-invasive UCB is common despite treatment; low and high grade tumors have recurrence rates of $50 \%-70 \%$ and more than $80 \%$, respectively. ${ }^{2-4}$ Stage progression occurs in $15 \%-20 \%$ of non-muscle-invasive cases. ${ }^{3,4}$ Muscle-invasive UCB entails a foreboding outlook in terms of progression and survival. Patients with muscle-invasive UCB have a significantly high risk for progression to regional and systemic disease, and regardless of treatment, the 5 -year overall survival (OS) rate of patients with muscle-invasive UCB is around $50 \% .^{5-7}$

The task of treating UCB is further constrained by the fact that it is primarily a disease of the elderly. In the United States, the median age of diagnosis is 73 years, which is the highest age of diagnosis compared with all other cancers. ${ }^{8}$ Age-related factors such as impaired renal function, higher frequency of comorbidities, and lower performance status can significantly affect treatment choices and the ability to treat in a timely fashion. The impact of such factors can be seen more clearly in patients with muscle-invasive, advanced, and metastatic UCB. Age-related factors render an estimated $30 \%-50 \%$ of patients unfit for cisplatin, and around $23 \%-50 \%$ of patients over the age of 65 receive either nonaggressive treatment or no treatment for muscleinvasive UCB. ${ }^{9-11}$ 
Through improved standards of current care, there has been a modest reduction in the number of deaths due to UCB. However, given the stark outcomes of UCB, we continually search for other potential avenues of treatment to bolster the current standards of care and offer an efficacious alternative for those patients deemed unfit for standard treatment. Additionally, there is an unmet need in those patients with metastatic disease who fail first-line systemic therapy. Ongoing improvements in our understanding of the biological pathophysiology of UCB have made targeted therapy an intensely investigated field for all stages of UCB given its impact on other cancers.

\section{Overview of current treatment options \\ Non-muscle-invasive bladder tumors}

Once a tumor or suspicious lesion has been identified, a transurethral resection of bladder tumor (TURBT) is the standard first-line treatment. TURBT serves a dual purpose; it is diagnostic for staging and therapeutic for noninvasive disease, except for carcinoma in situ (CIS). Most guidelines recommend a repeat TURBT if high grade disease is detected, since the risk of understaging is substantial and residual tumor can be found up to $50 \%$ of the time, particularly with $\mathrm{T} 1$ disease where the muscularis propria is not present in the surgical specimen ${ }^{12-16}$ (Table 1).

The next step in management involves the usage of intravesical therapy as either a prophylactic or adjuvant treatment. The intravesical agents are generally classified into 2 types: immunotherapy and chemotherapy.

The most common and widely used intravesical immunotherapy is bacillus Calmette-Guérin (BCG). It is considered to be the first-line treatment for CIS and the preferred adjuvant therapy for high grade and $\mathrm{T} 1$ disease. Tumor recurrence rates have been demonstrated to be reduced by up to $30 \%$, and

Table I Guideline treatment recommendations for non-muscle-invasive bladder cancer ${ }^{14-16}$

\begin{tabular}{|c|c|c|c|}
\hline & NCCN & AUA & EAU \\
\hline \multirow[t]{2}{*}{$\begin{array}{l}\text { Low risk } \\
\text { treatment }\end{array}$} & Low grade $\mathrm{Ta}$ tumor & Low grade Ta tumor & $\begin{array}{l}\text { EORTC-GU score } 0 \text { for } \\
\text { both recurrence and } \\
\text { progression }\end{array}$ \\
\hline & $\begin{array}{l}\text { TURBT. A single, postoperative instillation } \\
\text { of intravesical chemotherapy should be } \\
\text { considered. If bulky or multifocal, induction } \\
\text { chemotherapy should be considered }\end{array}$ & $\begin{array}{l}\text { TURBT. A single postoperative } \\
\text { instillation of intravesical } \\
\text { chemotherapy is recommended }\end{array}$ & $\begin{array}{l}\text { TURBT. A single } \\
\text { postoperative instillation } \\
\text { of intravescial chemotherapy } \\
\text { should be given }\end{array}$ \\
\hline \multirow[t]{2}{*}{$\begin{array}{l}\text { Intermediate risk } \\
\text { treatment }\end{array}$} & High grade $\mathrm{Ta}$ tumor & $\begin{array}{l}\text { Bulky or multifocal low grade } \\
\text { Ta tumor }\end{array}$ & $\begin{array}{l}\text { Recurrence score } 1-17 \text {, } \\
\text { progression score } 2-6\end{array}$ \\
\hline & $\begin{array}{l}\text { TURBT. Repeat resection if no } \\
\text { muscularis propria is found in the initial } \\
\text { TURBT specimen. Intravesical therapy, } \\
\text { preferably BCG, is optional }\end{array}$ & $\begin{array}{l}\text { TURBT. Induction course of either } \\
\text { BCG or MMC is recommended. } \\
\text { Maintenance therapy is optional }\end{array}$ & $\begin{array}{l}\text { TURBT. A single } \\
\text { postoperative instillation } \\
\text { of intravescial chemotherapy } \\
\text { should be given, followed } \\
\text { by induction BCG with } \\
\text { maintenance for I year } \\
\text { or further intravesical } \\
\text { chemotherapy for } \\
6-12 \text { months }\end{array}$ \\
\hline \multirow[t]{2}{*}{$\begin{array}{l}\text { High risk } \\
\text { treatment }\end{array}$} & All grades $\mathrm{TI}$ and $\mathrm{Tis}$ & $\begin{array}{l}\text { High grade } \mathrm{Ta} \text {, all grades } \\
\mathrm{TI} \text { and } \mathrm{Tis}\end{array}$ & Progression score 7-23 \\
\hline & $\begin{array}{l}\text { TURBT and repeat resection. } \\
\text { BCG therapy } 3-4 \text { weeks after } \\
\text { repeat resection is highly recommended. } \\
\text { Patients with pTis should receive an } \\
\text { induction course of BCG and at least } \\
\text { I year of maintenance BCG }\end{array}$ & $\begin{array}{l}\text { TURBT. A repeat resection } \\
\text { should be done if no muscularis } \\
\text { propria is found in the initial } \\
\text { TURBT specimen. BCG induction } \\
\text { with maintenance is recommended }\end{array}$ & $\begin{array}{l}\text { TURBT and repeat resection } \\
2-6 \text { weeks from the initial } \\
\text { TURBT. BCG induction and } \\
\text { maintenance for at least } \\
\text { I year. Patients with PTis } \\
\text { should receive BCG } \\
\text { induction and at least } \\
\text { I year of maintenance }\end{array}$ \\
\hline $\begin{array}{l}\text { Indications for } \\
\text { cystectomy }\end{array}$ & $\begin{array}{l}\text { High grade } \mathrm{TI} \text { with residual disease or } \\
\text { any recurrent disease refractory } \\
\text { to intravesical therapy }\end{array}$ & $\begin{array}{l}\text { Recurrent high risk disease } \\
\text { and BCG refractory disease }\end{array}$ & $\begin{array}{l}\text { Multifocal recurrent high } \\
\text { grade tumors, high grade } \\
\text { tumors with concomitant } \\
\text { CIS, BCG refractory disease }\end{array}$ \\
\hline
\end{tabular}

Abbreviations: NCCN, National Comprehensive Cancer Network; AUA, American Urological Association; EAU, European Association of Urology; TURBT, transurethral resection of bladder tumor; EORTC-GU, European Organization for Research and Treatment of Cancer Genito-Urinary; BCG, bacillus Calmette-Guérin; MMC, mitomycin-c; CIS, carcinoma in situ. 
a complete response (CR) has been achieved in 55\%-60\% of cases with small papillary tumors and up to $75 \%$ of CIS cases. ${ }^{17}$ Clinical trials conducted by the Southwest Oncology Group found that with additional maintenance therapy, the recurrence-free survival was noted to be twice as long compared with patients who had only received induction BCG therapy. ${ }^{18}$ BCG with maintenance therapy also has some impact on disease progression, with a $27 \%$ reduction in the odds of progression. ${ }^{19}$

The limitations of BCG are largely due to toxicity, with patients experiencing a high frequency of side effects that are mostly local in nature. In trials conducted by the European Organization for Research and Treatment of Cancer (EORTC), they found that $75 \%$ of patients experienced local side effects, most notably cystitis, and that toxicity caused treatment discontinuation in $20 \%$ and delay in $18 \%$ of patients..$^{20}$ Given its origins as a mycobacterium, BCG has the potential to cause a life-threatening sepsis, making it absolutely contraindicated in immunocompromised patients. ${ }^{21}$ Also, BCG treatment eventually fails in $30 \%-40 \%$ of patients, with another $30 \%-40 \%$ of patients who had a favorable initial response developing a recurrence within 5 years. ${ }^{22}$ These patients may be given a second induction course, with $\mathrm{CR}$ rates of $10 \%-20 \% .{ }^{23}$ Consecutive courses of BCG beyond a second induction were found to have a negative impact on outcomes by being associated with a $20 \%-50 \%$ risk of tumor progression..$^{24}$ Despite the greater morbidity associated with $\mathrm{BCG}$, the higher efficacy reported in numerous trials have made BCG the preferred intravesical therapy for superficial UCB (particularly high grade) among consensus panels of leading experts.

Interferon- $\alpha$ is another intravesical immunotherapy that has found some limited usage as an adjuvant after TURBT. Its usage is primarily hampered by high cost and inferior effectiveness as monotherapy compared with BCG and intravesical chemotherapy. However, interferon- $\alpha$ does have a favorable toxicity profile, rarely causing cystitis and occasionally resulting in brief flu-like symptoms. It has been investigated in a salvage setting for BCG failure in combination with low dose BCG, where a 2-year disease-free rate of $45 \%-53 \%$ was observed. ${ }^{25,26}$

Among the intravesical chemotherapy agents, mitomycin-c (MMC) is the most widely utilized. MMC reduces tumor recurrence rates by $15 \%$, and demonstrates a $50 \% \mathrm{CR}$ rate in patients with CIS. ${ }^{27,28}$ Despite the advantages of BCG in terms of treatment efficacy, MMC is a highly suitable option for low risk disease, due to its better toxicity profile compared with BCG. MMC can also be given immediately postoperatively, since there is no risk of sepsis from the drug itself. A meta-analysis conducted by the EORTC found that a single, postoperative dose of intravesical chemotherapy reduces the rate of recurrence by $11.7 \% .{ }^{29}$ However, based on the meta-analysis, the patients who were most likely to benefit from a single, postoperative instillation had small, solitary, low grade tumors.

Other chemotherapeutic agents which have been used for intravesical treatment include doxorubicin, epirubicin, valrubicin, and thiotepa. Valrubicin has a particular niche because it is approved by the Food and Drug Administration (FDA) in the United States for patients who have BCG refractory CIS disease and are not suitable candidates for extirpative surgery. A clinical trial conducted by Steinberg et al demonstrated a $21 \%$ CR rate, with a median follow-up of 30 months for patients with BCG refractory CIS of the bladder. ${ }^{30}$

\section{Muscle-invasive bladder tumors}

Radical cystectomy (RC) with extended pelvic lymph node dissection (PLND) and urinary diversion is the gold standard treatment for muscle-invasive UCB. This can be performed either open, laparoscopically, or more recently, robotic assisted. Surgical, intermediate-term oncologic, and functional outcomes for robotic-assisted RC are promising, but long-term outcomes are awaited. The PLND is important for staging and curative purposes. The extent of the lymph node dissection is controversial, and at least two randomized controlled trials are currently addressing this important question. ${ }^{31,32}$ Male urethrectomy (if the urethra is involved by tumor) is either performed at the time of or staged following $\mathrm{RC}$ depending on surgeon's preference. ${ }^{33}$ Either a continent or noncontinent urinary diversion is created, with the decision being made based on several factors including margin status, previous or expected pelvic radiation, the patient's ability to perform clean intermittent catheterizations, and surgeon/ patient preference. An orthotopic neobladder is commonly used as a bladder substitute, but if contraindicated, catheterizable pouches can be created with the continence mechanism based on an anatomic sphincteric valve (the ileocecal valve is a classic example). An ileal conduit is the most commonly used noncontinent diversion.

Other treatment options for muscle-invasive tumors include partial cystectomy in selected cases (a single small tumor situated away from the bladder base and ureteral orifices) and bladder sparing protocols which usually entail a multimodal approach of concurrent radiotherapy and sensitizing systemic chemotherapy following a maximal TURBT. Bladder preservation is an acceptable alternative for patients 
who are unfit for surgery due to extensive comorbidities or who refuse $\mathrm{RC}$ despite counseling. The 5-year OS rates for patients treated with bladder sparing protocols have been reported to be $48 \%-64 \%$. $^{7,34-36}$

Neoadjuvant systemic chemotherapy is recommended for patients with either muscle-invasive UCB exhibiting adverse clinicopathologic features or locally advanced UCB by both the National Comprehensive Cancer Network (NCCN) and the European Association of Urology (EAU), with the premise of treating micrometastatic disease prior to surgery ${ }^{14,37}$ (Table 2). Several randomized trials and meta-analyses show a $5 \%$ OS benefit in patient cohorts who receive neoadjuvant chemotherapy. 5,38,39 The equally efficacious platinum-based regimens of methotrexate, vinblastine, adriamycin, and cisplatin (MVAC) and gemcitabine and cisplatin (GC) are considered to be first-line systemic chemotherapy in UCB. Although MVAC is the historical standard in treating metastatic UCB, GC is more preferred given its favorable toxicity profile. ${ }^{40}$ For patients with impaired renal function, both the EAU and NCCN guidelines find that substituting carboplatin for cisplatin is acceptable. However, the NCCN recommends that those with borderline or minimal renal dysfunction should be considered for a split dose of cisplatin rather than carboplatin substitution ${ }^{14}$ (Table 2).

In patients with pT3-4 and/or node-positive disease, adjuvant systemic chemotherapy has been shown to improve survival in a few small randomized trials, with the advanced bladder cancer meta-analysis collaboration suggesting a $9 \%$ improvement in absolute survival at 3 years. ${ }^{41}$ However, these trials have been criticized for their small numbers and irregular treatment protocols. Given the paucity of larger studies on adjuvant chemotherapy, the EAU does not implicitly recommend its use after $\mathrm{RC} .{ }^{37}$ On the other hand, the NCCN believes it should be considered where the patient was not given chemotherapy neoadjuvantly.

\section{Metastatic UCB}

Unfortunately, surgery alone has no curative role in metastatic UCB, where platinum-based systemic chemotherapy is the mainstay of treatment for these patients. The NCCN additionally recommends that clinically abnormal lymph nodes should be biopsied if technically feasible. ${ }^{14}$ Also, the NCCN finds that offering radiotherapy with chemotherapy is acceptable except in cases of disseminated metastatic disease. The EAU makes two additional recommendations pertaining to systemic chemotherapy that are not approved for clinical use in North America: dose-dense (DD) MVAC in a first-line setting and vinflunine as a preferred second-line therapy. DD-MVAC is however currently being investigated in clinical trials across multiple NCCNaffiliated institutions. The EAU additionally recommends that either standard or DD-MVAC should be accompanied with granulocyte colony stimulating factor (GCSF), given the increased incidence of major neutropenic toxicities

Table 2 Guideline recommendations for systemic chemotherapy for urothelial carcinoma of the bladder ${ }^{14,37}$

\begin{tabular}{|c|c|c|}
\hline & NCCN & EAU \\
\hline $\begin{array}{l}\text { Indications for neoadjuvant } \\
\text { chemotherapy }\end{array}$ & $\begin{array}{l}\text { CT2 or cT3 (strongly consider) } \\
\text { disease }\end{array}$ & cT2 or cT3 disease \\
\hline $\begin{array}{l}\text { Indications for adjuvant } \\
\text { chemotherapy }\end{array}$ & $\begin{array}{l}\text { Consider for PT3-4 disease or } \\
\text { positive nodes, if no neoadjuvant } \\
\text { therapy was given }\end{array}$ & $\begin{array}{l}\text { Not indicated after cystectomy. } \\
\text { Should be given in a clinical trial } \\
\text { setting. Should not be given to } \\
\text { patients who cannot tolerate cisplatin }\end{array}$ \\
\hline $\begin{array}{l}\text { Indications for up-front } \\
\text { chemotherapy }\end{array}$ & $\begin{array}{l}\text { Clinically positive nodes, cT4, } \\
\text { and metastatic disease }\end{array}$ & $\begin{array}{l}\text { Clinically positive nodes, cT4, } \\
\text { and metastatic disease }\end{array}$ \\
\hline First-line regimens & GC (preferred), MVAC & $\begin{array}{l}\text { GC, MVAC (preferably with } \\
\text { GCSF), or DD-MVAC with GCSF }\end{array}$ \\
\hline Patients unfit for cisplatin & $\begin{array}{l}\text { If renal function is borderline or minimal } \\
\text { dysfunction, consider a split dose administration } \\
\text { (ie, } 35 \mathrm{mg} / \mathrm{m}^{2} \text { on days I and } 2 \text { or days I and } 8 \text { ). } \\
\text { Otherwise consider carboplatin and taxane-based } \\
\text { regimens as alternative first-line regimens or } \\
\text { single-agent therapy }\end{array}$ & $\begin{array}{l}\text { Carboplatin-containing combination } \\
\text { chemotherapy, preferably with } \\
\text { gemcitabine-carboplatin as first-line } \\
\text { treatment }\end{array}$ \\
\hline Second-line agents & $\begin{array}{l}\text { No standard, but patients should seek participation } \\
\text { of a clinical trial at this juncture }\end{array}$ & $\begin{array}{l}\text { Vinflunine (approved in Europe) } \\
\text { or participation in a clinical trial. } \\
\text { Zoledronic acid or denosumab are } \\
\text { recommended for bone metastasis }\end{array}$ \\
\hline
\end{tabular}

Abbreviations: NCCN, National Comprehensive Cancer Network; EAU, European Association of Urology; GC, gemcitabine + cisplatin; MVAC, methotrexate + vinblastine + doxorubicin (Adriamycin) + cisplatin; GCSF, granulocyte colony stimulating factor; DD, dose-dense. 
associated with the regimen. ${ }^{40}$ Although GCSF is commonly administered in the clinical setting, the NCCN does not explicitly include its use as a part of the guidelines. ${ }^{37}$

\section{New and emerging candidate agents}

Researchers have become more interested in developing novel targeted therapies and are currently exploring with agents that have proven useful in different organ sites (Table 3).

\section{Agents for muscle-invasive and advanced UCB}

\section{Angiogenesis inhibitors}

Vascular endothelial growth factor (VEGF) receptor inhibitors act by blocking angiogenesis, resulting in tumor hypoxia with subsequent ischemia and cell death. Sunitinib is a multiple tyrosine kinase inhibitor (TKI) which has been utilized for metastatic renal cell carcinoma (RCC), with a reported survival benefit. ${ }^{42}$ Bellmunt et al conducted a small Phase II study which included 38 patients with metastatic UCB who were unable to receive cisplatin and were treated with sunitinib $50 \mathrm{mg}$ daily in a 4 week on and 2 week off regimen. The reported median progression-free survival (PFS) and OS was 4.3 and 8.1 months, respectively. A partial response (PR) was noted in $8 \%$ of patients, while $50 \%$ had stable disease (SD) for more than 3 months. ${ }^{43}$ A Phase II study examined sunitinib as a second-line agent for 77 previously treated patients with metastatic UCB. Patients were divided into two cohorts; 45 patients received $50 \mathrm{mg}$ of sunitinib per day for 4 weeks on and 2 weeks off (cohort A), while 32 received $37.5 \mathrm{mg}$ per day continuously (cohort B). A PR was noted in $7 \%$ of cohort A as compared with $3 \%$ in cohort B. Forty-three percent had $\mathrm{SD}$, with the PFS and OS being similar in both cohorts, 2.4 versus 2.3 months and 7.1 versus 6.0 months, respectively. ${ }^{44}$ A clinical trial further investigating the impact of sunitinib on advanced UCB is the SUCCINCT trial (available at http:// www.cancerresearchuk.org/cancer-help/trials/trials-search/ trial-cisplatin-gemcitabine-sunitinib-advanced-transitionalcell-cancer-urinary-sytem-SUCCINCT). It is a Phase II study in the UK that aims to recruit 63 patients to investigate the efficacy of sunitinib in combination with GC as a first-line treatment (Table 4).

Sorafenib, anotherTKI including VEGF receptors 2 and 3 , has been investigated in at least two Phase II studies. Sridhar and colleagues have reported their outcomes on 17 patients with metastatic disease who received sorafenib as a first-line therapy. No objective response was noted, and the median time to progression (TTP) and OS were 1.9 and 5.9 months, respectively. ${ }^{45}$ Dreicer et al conducted a Phase II trial with sorafenib in a second-line setting for metastatic UCB. They also reported no objective response amongst the 22 eligible patients treated and determined the median PFS and OS of their cohort to be 2.2 and 6.8 months, respectively. ${ }^{46}$ Both investigators concluded that sorafenib as single agent therapy was not clinically meaningful in the first- and second-line settings. However, given the cytostatic nature of sorafenib in other cancers, the investigators believe that it can be investigated as maintenance therapy for those patients who respond to first-line chemotherapy. A Phase II trial is currently active in Italy investigating sorafenib in combination with GC in a neoadjuvant setting with a recruitment goal of 45 patients to assess pathologic response to the investigational regimen.

Pazopanib, a TKI including VEGF receptors 1-3 and platelet-derived growth factor receptor has been observed to have antineoplastic activity against UCB in preclinical studies. ${ }^{47} \mathrm{~A}$ recently completed Phase II trial utilizing pazopanib conducted by Necchi et al treated 41 patients with advanced UC ( 26 with primary UCB) who had failed platinum-based chemotherapy. Seven (17.1\%) had partial response and 14 (34.2\%) had confirmed SD, with a median PFS and OS of 2.6 and 4.7 months, respectively. ${ }^{48}$ Active Phase II studies are examining pazopanib in combination with gemcitabine in a first-line setting for patients with advanced UCB who are unfit for cisplatin (Table 4).

Dovitinib (TKI258) is another example of a TKI which also has shown activity against fibroblast growth factor receptor-dependent UCB growth within laboratory studies. ${ }^{49}$ A Phase II trial with 44 patients with advanced UCB with disease progression despite first-line therapy has recently completed with results pending (Table 4).

Bevacizumab is a monoclonal antibody of VEGF and also blocks tumor angiogenesis. It is a well established RCC agent that was examined in a Phase II study with 43 patients with metastatic UCB given in combination with GC. The study demonstrated an overall response rate (RR) of $72 \%$, with $19 \%$ having a CR and 53\% a PR. The median PFS was 8.2 months and median OS was 19.1 months. ${ }^{50}$ A multicenter Phase III randomized double-blind study is active using bevacizumab with GC in a first-line setting for patients with advanced or metastatic UCB. This study aims to enroll 500 patients, with the primary objective of assessing OS of patients who received $\mathrm{GC}$ with bevacizumab versus those who received GS with placebo.

Aflibercept is a human recombinant fusion protein that binds VEGF with greater affinity than monoclonal antibodies, 


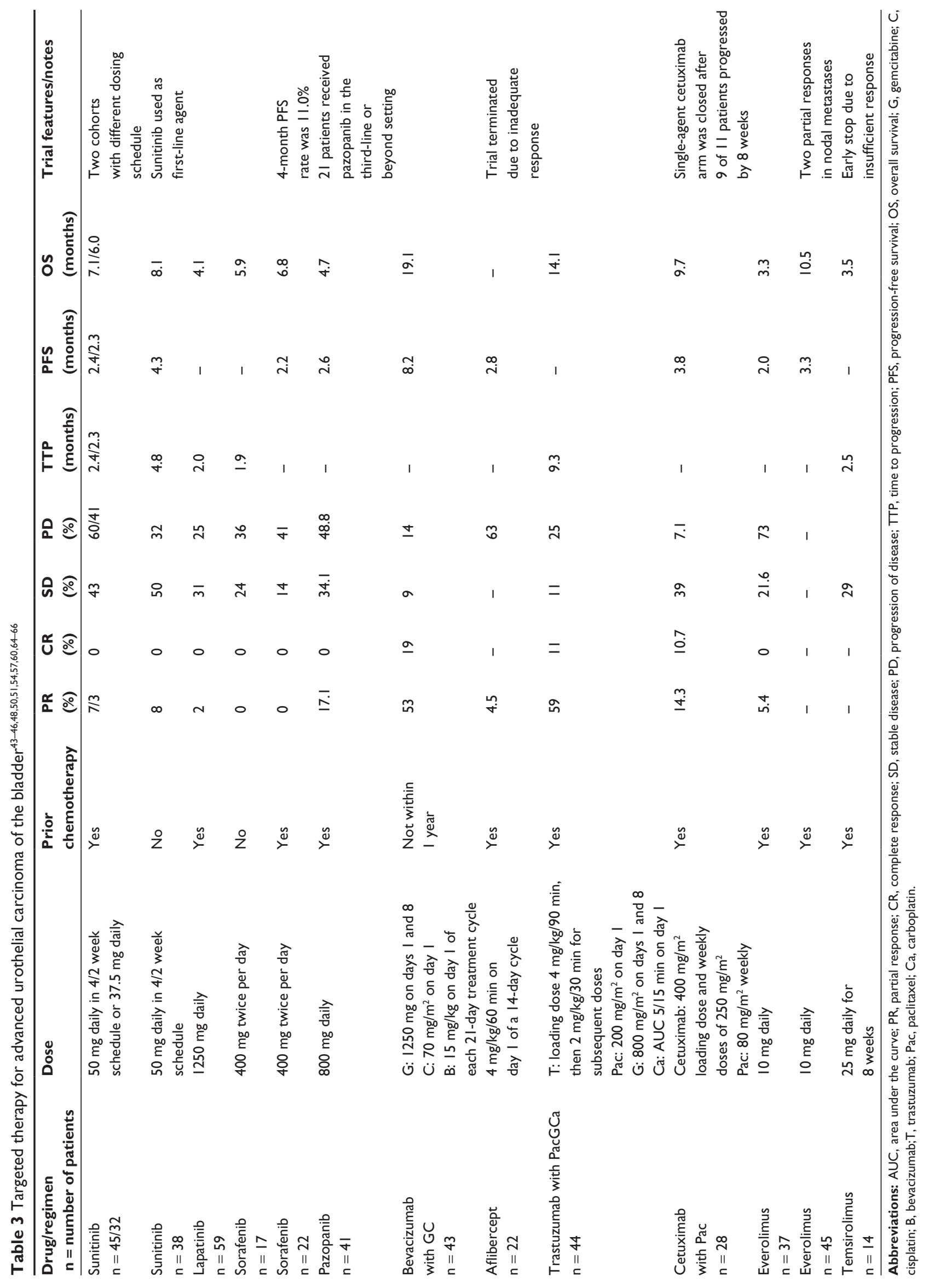


and neutralizes multiple VEGF isoforms. In a Phase II trial, Twardowski and colleagues treated 22 patients with advanced UC who had failed platinum-based regimen, with $4 \mathrm{mg} / \mathrm{kg}$ intravenously every 2 weeks and reported one PR (4.5\%) and median PFS of 2.79 months. The drug was well tolerated. ${ }^{51}$

\section{Tumorigenesis inhibitors}

Epidermal growth factor receptor (EGFR) and human epidermal receptor 2 (HER2/neu) are often overexpressed in malignant urothelial cells. Overexpression of HER2/neu, which occurs in about $28 \%$ of primary urothelial tumors and more than $50 \%$ of metastatic tumors, has been associated with higher tumor grade, invasiveness, and increased metastatic potential. ${ }^{52,53}$ Lapatinib, is a TKI that blocks both of these receptors, with subsequent decrease in cell growth. Wulfing et al reported their outcomes with lapatinib from a multicenter Phase II study of 59 patients with locally advanced or metastatic UCB refractory to first-line systemic chemotherapy. An objective RR of less than $10 \%$ was noted in $1.7 \%$ of patients. However, $31 \%$ achieved SD, with a median TTP and OS of 8.6 weeks and 17.9 weeks, respectively. They also noted that patients experiencing clinical response overexpressed EGFR and/or HER2/neu. ${ }^{54}$ Lapatinib is currently being investigated in patients with advanced UCB who have responded to chemotherapy and express EGFR or HER2/neu receptors (Table 4).

Trastuzumab, a well recognized HER2/neu monoclonal antibody used in the treatment of breast cancer, has been studied in advanced UCB. Pilot studies show that monotherapy with trastuzumab has limited activity against UCB, but when combined with cytotoxic chemotherapy, has more modest results. ${ }^{5,56}$ Hussain et al conducted a Phase II study with trastuzumab in combination with paclitaxel, gemcitabine, and carboplatin in patients with advanced UC, overexpressing HER2/neu. They

Table 4 Ongoing and planned clinical trials of novel agents/regimens for muscle-invasive and advanced urothelial carcinoma of the bladder

\begin{tabular}{|c|c|c|c|c|c|}
\hline Drug/regimen & $\begin{array}{l}\text { Study numberl } \\
\text { name }\end{array}$ & Institution & Trial phase & $\begin{array}{l}\text { Drug/regimen } \\
\text { setting }\end{array}$ & Enrollment \\
\hline GC-sunitinib & SUCCINCT & Multicenter (UK) & Phase II & First-line & 63 \\
\hline GC-sunitinib & NCT008470I5 & MSKCC & Phase II & Neoadjuvant & 18 \\
\hline Sunitinib & NCT0I042795 & U Michigan & Phase II & Adjuvant & 33 \\
\hline GC-sorafenib & NCTOI 222676 & Italy & Phase II & Neoadjuvant & 45 \\
\hline Lapatinib & LaMB & Multicenter (UK) & Phase II & First-line consolidation & 204 \\
\hline GC/GCa-dovitinib & NCTOI496534 & Mount Sinai & Phase I & First-line & 24 \\
\hline Dovitinib (TKI258) & NCT00790426 & Multicenter (International) & Phase II & Second-line & 44 \\
\hline GCa-vandetanib & TOUCAN & Multicenter (UK) & Phase II & First-line & 122 \\
\hline Dasatanib & NCT0070664I & Baylor-HOG & Phase 0 & Neoadjuvant & 25 \\
\hline G-pazopanib & NCT0I 622660 & MSKCC & Phase II & First-line, renal dys & 45 \\
\hline Pac-pazopanib & NCTOII08055 & Stanford/Karmanos & Phase II & Salvage & 32 \\
\hline Docetaxel-gefitinib & NCT00479089 & MDACC & Phase II & Second-line consolidation & 90 \\
\hline Cabozantinib & NCT0I688999 & $\mathrm{NCl}$ & Phase II & Salvage & 55 \\
\hline Erlotinib & NCT00380029 & U North Carolina & Phase II & Neoadjuvant & 27 \\
\hline Erlotinib & NCT00749892 & MDACC & Phase II & Neoadjuvant & 42 \\
\hline GC-bevacizumab & NCT0094233I & $\mathrm{NCl} /$ Multicenter & Phase III & First-line & 500 \\
\hline GC-cetuximab & NCT00645593 & U Michigan/multicenter & Phase II & First-line & 89 \\
\hline Cetuximab-Pac & NCT00350025 & Fox Chase & Phase II & Second-line & 34 \\
\hline Cetuximab-(C or & TUXEDO & Multicenter (UK) & Phase I/II & Second-line consolidation & 60 \\
\hline \multicolumn{6}{|l|}{ MMC-5FU) + RT } \\
\hline Pac-RT-trastuzumab & NCT00238420 & Multicenter/NCl & Phase I/II & First-line, bladder sparing & 88 \\
\hline Everolimus & NCT00805I 29 & MSKCC & Phase II & Second-line & 46 \\
\hline G-split dose & NCT0II82I68 & MSKCC & Phase I & First-line & 30 \\
\hline \multicolumn{6}{|l|}{ C-everolimus } \\
\hline Everolimus-Pac & NCT0I2I5I36 & HOG & Phase II & First-line, cisplatin ineligible & 68 \\
\hline GC-temsirolimus & NCT0I090466 & Multicenter (UK) & Phase I/II & First-line & 99 \\
\hline BKMI20 & NCT0I55I030 & MSKCC & Phase II & Second-line & 35 \\
\hline DN24-02 & NCTOI 353222 & Multicenter & Phase II & Adjuvant & 180 \\
\hline GC-OGX-427 & NCT0I454089 & Multicenter & Phase II & First-line & 180 \\
\hline GC-ALT-80I & NCT0I32687I & Multicenter & Phase I/II & First-line & 76 \\
\hline GC-Ipilimumab & NCT0I52499I & HOG & Phase II & First-line & 36 \\
\hline
\end{tabular}

Abbreviations: G, gemcitabine; C, cisplatin; Ca, carboplatin; Pac, paclitaxel; MMC, mitomycin-c; 5-FU, 5-fluorouracil; RT, radiation therapy. 
treated 44 with this regimen and reported a $70 \% \mathrm{RR}$, with a median TTP and OS of 9.3 and 14.1 months, respectively. ${ }^{57}$

Cetuximab is a monoclonal antibody to the EGFR pathway which has previously shown effect to head and neck tumors and is now being studied in UCB. The EGFR pathway is important in cell regeneration and has been shown to be overexpressed in UCB and associated with a worse progno$\operatorname{sis}^{58,59}$ and therefore constitutes a potential target for EGFR inhibitors such as cetuximab and gefitinib, another TKI which inhibits EGFR. Wong et al performed a randomized Phase II trial comparing cetuximab with or without paclitaxel, with 39 patients with metastatic UCB who progressed despite receiving first-line therapy. They noted that cetuximab had limited activity as a single agent but appeared to augment the antitumor activity of paclitaxel ${ }^{60}$ Currently, there is a trial in the UK examining cetuximab in combination with radiotherapy and different types of chemotherapy for muscle-invasive UCB (TUXEDO trial, available at http://www.cancerresearchuk. org/cancer-help/trials/a-trial-of-cetuximab-with-chemotherapy-and-radiotherapy-for-muscle-invasive-bladder-cancertuxedo). Gefitinib has not shown any significant survival benefit but is currently being investigated with docetaxel as second-line consolidation therapy (Table 4).

Other TKIs and monoclonal antibodies (dasatinib, vandetanib, pazopanib, erlotinib, and trastuzumab) are currently being investigated as well (Table 4).

\section{Inhibitors of the PI3K-Akt-mTOR pathway}

The mammalian target of rapamycin (mTOR) is a part of an intracellular signaling pathway that governs over cell growth and proliferation. In a variety of different malignancies, the activation of the mTOR pathway is left unchecked, resulting in uncontrolled cell proliferation. Everolimus inhibits the mTOR pathway and has been used for refractory advanced RCC, with a reported improvement in PFS. ${ }^{61}$ The clinical implications of this pathway have been shown for muscle-invasive urothelial tumors as well, and its urothelial antitumor activity has been demonstrated in both in-vitro and in-vivo models. ${ }^{62,63}$ Seront et al performed a Phase II trial using everolimus in a second-line setting among 37 patients with advanced UCB who had disease progression after first-line chemotherapy, with cancer control rates at 8 weeks being the primary endpoint. Disease control rate was defined as SD, PR, or CR. At 8 weeks, $27 \%$ had reached the primary endpoint (two patients had a PR and eight had SD). ${ }^{64}$ Milowsky et al further examined everolimus in a Phase II trial on 45 patients with advanced UC, who had progressed on chemotherapy.
The drug was reasonably well tolerated with some grade 3/4 toxicity reported, and the median PFS and OS were 3.3 and 10.5 months, respectively. ${ }^{65}$ A Phase II study is underway studying everolimus with and without paclitaxel in the first-line setting for patients with advanced and metastatic UCB who are unfit for cisplatin. This study hopes to recruit 68 patients, with measuring RR at 4 months as the primary objective.

Gerullis and associates reported modest response rates to temsirolimus in patients who relapsed after first-line chemotherapy for metastatic UCB. SD was found in 4 of the 14 patients who participated in the study. The median TTP and OS were 2.5 months and 3.5 months, respectively. ${ }^{66}$ Unfortunately, they had stopped the trial early since the median OS did not reach the primary endpoint of an OS of 6 months. A multicenter Phase I/II study in the UK is investigating temsirolimus in combination with $\mathrm{GC}$ in the first-line setting for advanced and metastatic UCB. The study aims to enroll 99 patients, with the primary endpoint of assessing PFS at 6 months.

The phosphatidylinositol 3-kinases (PI3K) are lipid kinases whose products participate in the PI3K-Akt-mTOR signaling cascades that regulate cell survival, proliferation, motility, and differentiation. Uncontrolled activation of class IA PI3K has been discovered to be intimately involved in the pathogenesis of cancer including UCB. ${ }^{67-69}$ BKM120 is a pan-class I PI3K inhibitor that is currently being studied in a Phase II trial for patients with metastatic UCB who have failed first-line chemotherapy. The study plans to enroll 35 patients, with the primary endpoint being PFS at 2 months (Table 4).

\section{Immunotherapy}

Immunotherapy has been studied in many solid tumor types, with BCG, sipuleucel-T, IL-2, and interferon- $\alpha$ being good examples of successful agents used for bladder, prostate, and kidney cancers. Vaccines are now being developed against tumor cells, with promising preliminary results reported. The NY-ESO-1 recombinant protein vaccine was designed to recognize NY-ESO-1 antigen, which is predominantly expressed in high grade urothelial tumors. ${ }^{70}$ This vaccine was tested in a Phase I trial on six patients who had undergone RC or nephroureterectomy and were not candidates for adjuvant systemic chemotherapy. It was administered in combination with intradermal BCG and subcutaneous GCSF to further boost a vaccine-induced immune response. The vaccine was well tolerated, and all of the patients showed immune responses. ${ }^{71}$ Another study conducted by Zhang et al 
demonstrated that dendritic cell vaccine modified by the Ag85A gene enhanced antitumor immunity against bladder cancer, with a significant inhibitory effect on tumor growth in murine models. ${ }^{72}$

Survivin, an anti-apoptosis protein, is expressed by many tumors, including UCB. ${ }^{73,74}$ Honma et al vaccinated nine patients with advanced UCB against survivin-2B80-88 peptide to assess safety and efficacy. They had previously demonstrated how this peptide in conjunction with human leukocyte antigen class I stimulates a $\mathrm{CD}^{+}$cytotoxic T-lymphocyte (CTL) response. ${ }^{74,75}$ Measurable increases in CTL against the survivin peptide were detected in five patients, and one patient had slight reduction in tumor volume. ${ }^{76}$

Ipilimumab is a fully humanized monoclonal antibody directed against cytotoxic $\mathrm{T}$ lymphocyte associated antigen (CTLA-4), a regulatory molecule found on the surface of activated $\mathrm{T}$ cells and subsets of regulatory $\mathrm{T}$ cells. It has been recently approved by the FDA for the treatment of metastatic melanoma. Ipilimumab has been demonstrated in a preclinical trial to generate an immune response in patients with organ-confined UCB. ${ }^{77}$ The primary marker chosen to measure response is inducible costimulator (ICOS)expressing CD4 T cells (CD4 $\left.{ }^{+} \mathrm{ICOS}^{\mathrm{hi}}\right)$, as it is thought to be a marker of T-cell activation and, interestingly, can recognize NY-ESO-1 antigen. ${ }^{78}$ Persistent increases in $\mathrm{CD}^{+} \mathrm{ICOS}^{\mathrm{hi}}$ have been associated with improved survival in a small retrospective cohort of patients with metastatic melanoma who received ipilimumab. ${ }^{77} \mathrm{~A}$ Phase II trial is currently active assessing $\mathrm{GC}$ with ipilimumab in a first-line setting for patients with metastatic UCB (Table 4). This study plans to enroll 36 patients, with the primary objective of determining 1 -year OS in this cohort.

\section{Agents for non-muscle-invasive UCB}

Some of the new candidate drugs' mechanism of action is to deliver traditional therapies in a more effective manner. Apaziquone, a synthetic derivative of MMC, relies on deoxythymidine-diaphorase, a cellular reductase enzyme that has been found to be highly active in $40 \%$ of bladder tumors, to make it more cytotoxically active. ${ }^{79}$ This activation property is particularly important because traditional intravesical therapies' most common side effect is chemical cystitis, which is one of the primary reasons why patients cannot tolerate repeated drug delivery and subsequently leads to altered and/or inadequate treatment courses. Phase II studies of apaziquone have reported that the incidence of bacterial and chemical cystitis range between $11 \%$ and $34 \%$, compared with BCG, doxorubicin, and MMC which have incidence rates of cystitis up to $80 \%, 56 \%$, and $41 \%$; respectively. ${ }^{80}$ Apaziquone shows promise in a Phase II trial done in the Netherlands using it as an adjuvant therapy after TURBT for high risk non-muscle-invasive tumors, yielding recurrence rates of $34.7 \%$ at 12 months and $44.9 \%$ at 18 months. ${ }^{80}$ Currently, Phase III multicenter trials with apaziquone as an adjuvant treatment for non-muscle-invasive UCB are ongoing (Table 5).

Table 5 Ongoing and planned clinical trials of novel agents/regimens for non-muscle-invasive urothelial carcinoma of the bladder

\begin{tabular}{|c|c|c|c|c|c|}
\hline Drug/regimen & $\begin{array}{l}\text { Study numberl } \\
\text { name }\end{array}$ & Institution & Trial phase & $\begin{array}{l}\text { Drug/regimen } \\
\text { setting }\end{array}$ & Enrollment \\
\hline Allopurinol & RAPOR & UK & Phase II & $\begin{array}{l}\text { Low grade } \\
\text { chemorefractory }\end{array}$ & 64 \\
\hline $\begin{array}{l}\text { Postop MMC + celecoxib- } \\
\text { (MMC/BCG) }\end{array}$ & BOXIT & Multicenter (UK) & Phase III & Adjuvant & 475 \\
\hline $\begin{array}{l}\text { DEPDCI-9-294, MPHOSPHI- } \\
\text { 9-278 peptide vaccines }\end{array}$ & NCT00633204 & Iwate Univ (Japan) & Phase II & $\begin{array}{l}\text { Prevention after } \\
\text { TURBT }\end{array}$ & 150 \\
\hline $\begin{array}{l}\text { INSTILADRIN (rAd-IFN } \\
\text { with Syn3) }\end{array}$ & NCTOI687244 & Multicenter & Phase II & BCG refractory & 40 \\
\hline Valproate & NCTOI7388I5 & SUNY-Upstate & Phase 0 & Before TURBT & 50 \\
\hline DTA-HI9/PEI & NCT00595088 & Multicenter (Israel) & Phase II & Refractory, second-line & 39 \\
\hline ALT-80I & NCT0I 625260 & MDACC Orlando & Phase I/II & Refractory, second-line & 52 \\
\hline Lenalidomide-BCG & NCT0I373294 & HLMCC & Phase II & Adjuvant & 70 \\
\hline Dovitinib & NCT0I732107 & HOG & Phase II & $\mathrm{BCG}$ refractory & 50 \\
\hline EO9 (Apaziquone) & NCT0I475266 & $\begin{array}{l}\text { Multicenter } \\
\text { (Korea + Japan) }\end{array}$ & Phase II/III & $\begin{array}{l}\text { Immediate postoperative } \\
\text { adjuvant }\end{array}$ & 120 \\
\hline Apaziquone & NCT0I46922I & $\begin{array}{l}\text { Multicenter } \\
\text { (International) }\end{array}$ & Phase III & Adjuvant & 658 \\
\hline $\begin{array}{l}\text { Everolimus-intravesical } \\
\text { gemcitabine }\end{array}$ & NCTOI 259063 & MSKCC & Phase I/II & $\mathrm{BCG}$ refractory $\mathrm{CIS}$ & 45 \\
\hline
\end{tabular}

Abbreviations: BCG, bacillus Calmette-Guérin; MMC, mitomycin-c; IFN, interferon- $\alpha$; TURBT, transurethral resection of bladder tumor; CIS, carcinoma in situ. 
Another emerging candidate for intravesical use is oportuzumab monatox $(\mathrm{OM})$, a recombinant fusion protein consisting of humanized anti-epithelial cell adhesion molecule (EpCAM) antibody linked to Pseudomonas exotoxin A. ${ }^{81}$ Though EpCAM can be overexpressed in many different cancers, in UCB, the level of EpCAM overexpression was found to be associated with the grade of the disease; high grade tumors express more EpCAM compared with low grade tumors, making it clinically relevant for targeted therapy. ${ }^{82}$ Phase I and II trials have been conducted investigating OM for non-muscle-invasive UCB among patients who were BCG refractory or could not tolerate prior BCG therapy. The Phase I trials observed an overall CR rate of $39 \% .{ }^{81}$ In Phase II trials, Kowalski et al explored the efficacy of OM, specifically for BCG-refractory CIS disease. They achieved a CR rate of $27 \%$ at 6 months, with $16 \%$ remaining disease free at 1 year. ${ }^{83}$ In comparison, valrubicin produced a CR in $21 \%$, with $8 \%$ remaining disease free at a median follow-up of 30 months. ${ }^{30}$ Adverse events related to OM were reported in $31 \%$ and $65 \%$ of patients for the Phase I and II studies, respectively, with mild dysuria being the most commonly reported side effect in both studies. ${ }^{83}$

Conventional drugs commonly used in general practice are being investigated as possible preventative agents for superficial UCB. The Bladder COX Inhibition Trial (BOXIT) was designed to reduce the risk of recurrent superficial bladder cancer, with standard therapy and celecoxib (a nonsteroidal anti-inflammatory agent (COX-2 inhibitor)). The COX-2 inflammatory response mediator has been observed to be overexpressed in UCB. ${ }^{84}$ BOXIT is a Phase III randomized controlled study, with a recruitment goal of 475 patients among newly diagnosed or recurrent superficial UCB who underwent TURBT and a single postoperative MMC instillation followed by an induction course of MMC or BCG with either oral celecoxib or a placebo drug over a 2-year period. Recruitment ended in August 2012, with the results pending. Allopurinol, an inhibitor of xanthine oxidase attributed to gout, is also being investigated as a preventative agent, on the basis that xanthine oxidase has been reported to have increased activity in patients with papillary $\mathrm{UCB}^{85}$ (Table 5).

\section{Conclusion}

UCB is a complex disease which is often difficult to manage given the chemorefractory and high recurrence rates of these tumor types. With an increasing understanding of cancer biology, new agents have been proposed and evaluated with variable reported results for both noninvasive and more advanced disease. Intravesical agents have been used to reduce the risk of recurrence and progression of UC, with several new drugs such as apaziquone and OM having shown promising results in Phase II trials. Platinum-based cytotoxic systemic chemotherapy is the first-line treatment option for both organ-confined muscle-invasive and advanced UCB (in the neoadjuvant, adjuvant, and/or metastatic settings) but with a limited survival benefit, paving the way for alternative systemic approaches. Targeted agents aimed at different molecular pathways (VEGF, EGFR, mTOR) and immunotherapy have been developed and preliminarily investigated for other tumor types, with favorable initial results within the different clinical presentation spectrums of UCB. A select few of these targeted agents have shown modest survival benefits as second-line single agents in advanced UCB, but unfortunately most of these studies are small and nonrandomized. Instead, the results from trials indicate the need for more unique strategies to treat the complex nature of UCB. Few Phase III trials are currently being conducted using targeted agents in the second-line setting, but nevertheless at the present time, we recommend that clinicians treating UCB adhere to accepted treatment guidelines but keep abreast of these exciting developments in our evolving therapeutic approaches to this often highly aggressive tumor phenotype.

\section{Disclosure}

The authors report no conflicts of interest in this work.

\section{References}

1. Ploeg M, Aben KK, Kiemeney LA. The present and future burden of urinary bladder cancer in the world. World J Urol. 2009;27(3): 289-293.

2. Herr HW. Tumor progression and survival of patients with high grade, noninvasive papillary (TaG3) bladder tumors: 15 -year outcome. J Urol. 2000;163(1):60-61; discussion 61-62.

3. Millan-Rodriguez F, Chechile-Toniolo G, Salvador-Bayarri J, Palou J, Algaba F, Vicente-Rodriguez J. Primary superficial bladder cancer risk groups according to progression, mortality and recurrence. $J$ Urol. 2000;164(3 Pt 1):680-684.

4. Sylvester RJ, van der Meijden AP, Oosterlinck W, et al. Predicting recurrence and progression in individual patients with stage Ta $\mathrm{T} 1$ bladder cancer using EORTC risk tables: a combined analysis of 2596 patients from seven EORTC trials. Eur Urol. 2006;49(3):466-475; discussion 475-477.

5. Grossman HB, Natale RB, Tangen CM, et al. Neoadjuvant chemotherapy plus cystectomy compared with cystectomy alone for locally advanced bladder cancer. N Engl J Med. 2003;349(9):859-866.

6. Stein JP, Skinner DG. Radical cystectomy for invasive bladder cancer: long-term results of a standard procedure. World J Urol. 2006; 24(3):296-304

7. Efstathiou JA, Spiegel DY, Shipley WU, et al. Long-term outcomes of selective bladder preservation by combined-modality therapy for invasive bladder cancer: the MGH experience. Eur Urol. 2012;61(4):705-711.

8. Siegel R, DeSantis C, Virgo K, et al. Cancer treatment and survivorship statistics, 2012. CA Cancer J Clin. 2012;62(4):220-241. 
9. Fedeli U, Fedewa SA, Ward EM. Treatment of muscle invasive bladder cancer: evidence from the National Cancer Database, 2003 to 2007. J Urol. 2011;185(1):72-78.

10. Dash A, Galsky MD, Vickers AJ, et al. Impact of renal impairment on eligibility for adjuvant cisplatin-based chemotherapy in patients with urothelial carcinoma of the bladder. Cancer. 2006;107(3): 506-513.

11. Schrag D, Mitra N, Xu F, et al. Cystectomy for muscle-invasive bladder cancer: patterns and outcomes of care in the Medicare population. Urology. 2005;65(6):1118-1125.

12. Grimm MO, Steinhoff C, Simon X, Spiegelhalder P, Ackermann R, Vogeli TA. Effect of routine repeat transurethral resection for superficial bladder cancer: a long-term observational study. J Urol. 2003;170(2 Pt 1): 433-437.

13. Dutta SC, Smith JA Jr, Shappell SB, Coffey CS, Chang SS, Cookson MS. Clinical under staging of high risk nonmuscle invasive urothelial carcinoma treated with radical cystectomy. J Urol. 2001;166(2):490-493.

14. Bladder Cancer Version 2. Jenkintown (PA): National Comprehensive Cancer Network (NCCN); 2011. Clinical Practice Guidelines in Oncology, Version 2. 2012. Available from: http://www.nccn.org/professionals/ physician_gls/pdf/bladder.pdf. Accessed July 18, 2012.

15. Babjuk M, Oosterlinck W, Sylvester R, et al; European Association of Urology (EAU). EAU guidelines on non-muscle-invasive urothelial carcinoma of the bladder, the 2011 update. Eur Urol. 2011;59(6):997-1008.

16. Hall MC, Chang SS, Dalbagni G, et al. Guideline for the management of nonmuscle invasive bladder cancer (stages Ta, T1, and Tis): 2007 update. J Urol. 2007;178(6):2314-2330.

17. O'Donnell MA. Advances in the management of superficial bladder cancer. Semin Oncol. 2007;34(2):85-97.

18. Lamm DL, Blumenstein BA, Crissman JD, et al. Maintenance bacillus Calmette-Guerin immunotherapy for recurrent TA, T1 and carcinoma in situ transitional cell carcinoma of the bladder: a randomized Southwest Oncology Group Study. J Urol. 2000;163(4):1124-1129.

19. Sylvester RJ, van der MA, Lamm DL. Intravesical bacillus CalmetteGuerin reduces the risk of progression in patients with superficial bladder cancer: a meta-analysis of the published results of randomized clinical trials. J Urol. 2002;168(5):1964-1970.

20. van der Meijden AP, Sylvester RJ, Oosterlinck W, Hoeltl W, Bono AV. Maintenance bacillus Calmette-Guerin for Ta T1 bladder tumors is not associated with increased toxicity: results from a European Organisation for Research and Treatment of Cancer Genito-Urinary Group Phase III Trial. Eur Urol. 2003;44(4):429-434.

21. Rawls WH, Lamm DL, Lowe BA, et al. Fatal sepsis following intravesical bacillus Calmette-Guerin administration for bladder cancer. J Urol. 1990;144(6):1328-1330.

22. Lamm DL, Blumenstein BA, Crawford ED, et al. A randomized trial of intravesical doxorubicin and immunotherapy with bacille CalmetteGuerin for transitional-cell carcinoma of the bladder. $N$ Engl J Med. 1991;325(17):1205-1209.

23. Witjes JA, Hendricksen K. Intravesical pharmacotherapy for nonmuscle-invasive bladder cancer: a critical analysis of currently available drugs, treatment schedules, and long-term results. Eur Urol. 2008;53(1):45-52.

24. Nadler RB, Catalona WJ, Hudson MA, Ratliff TL. Durability of the tumor-free response for intravesical bacillus Calmette-Guerin therapy. J Urol. 1994;152(2 Pt 1):367-373.

25. O'Donnell MA, Krohn J, DeWolf WC. Salvage intravesical therapy with interferon-alpha $2 \mathrm{~b}$ plus low dose bacillus Calmette-Guerin is effective in patients with superficial bladder cancer in whom bacillus CalmetteGuerin alone previously failed. J Urol. 2001;166(4):1300-1304, discussion 1304-1305.

26. Joudi FN, Smith BJ, O’Donnell MA. Final results from a national multicenter Phase II trial of combination bacillus Calmette-Guerin plus interferon alpha-2B for reducing recurrence of superficial bladder cancer. Urol Oncol. 2006;24(4):344-348.
27. Sylvester RJ, van der Meijden AP, Witjes JA, Kurth K. Bacillus calmetteguerin versus chemotherapy for the intravesical treatment of patients with carcinoma in situ of the bladder: a meta-analysis of the published results of randomized clinical trials. J Urol. 2005;174(1):86-91; discussion 91-92.

28. Shelley MD, Court JB, Kynaston H, Wilt TJ, Coles B, Mason M. Intravesical bacillus Calmette-Guerin versus mitomycin $\mathrm{C}$ for Ta and T1 bladder cancer. Cochrane Database Syst Rev. 2003;3: CD003231.

29. Sylvester RJ, Oosterlinck W, van der Meijden AP. A single immediate postoperative instillation of chemotherapy decreases the risk of recurrence in patients with stage Ta T1 bladder cancer: a meta-analysis of published results of randomized clinical trials. J Urol. 2004;171(6 Pt 1): 2186-2190, quiz 2435.

30. Steinberg G, Bahnson R, Brosman S, Middleton R, Wajsman Z, Wehle M. Efficacy and safety of valrubicin for the treatment of Bacillus Calmette-Guerin refractory carcinoma in situ of the bladder. The Valrubicin Study Group. J Urol. 2000;163(3):761-767.

31. Association of Urogenital Oncology (AUO). Limited vs Extended Lymphadenectomy LEA. In: ClinicalTrials.gov [website on the Internet]. Bethesda, MD: US National Library of Medicine; 2010 [updated September 7, 2011]. Available from: http://clinicaltrials.gov/ ct2/show/NCT01215071. NLM identifier: NCT01215071. Accessed November 19, 2012.

32. S1011: Radical cystectomy for bladder cancer: how many lymph nodes to take? [webpage on the Internet] SWOG (formerly Southwestern Oncology Group), 2011. Available from: http:/www.swog.org/Visitors/ newsletters/2011/08/index.asp? $\mathrm{a}=\mathrm{s} 1011$. Accessed November 19, 2012.

33. Spiess PE, Kassouf W, Brown G, et al. Immediate versus staged urethrectomy in patients at high risk of urethral recurrence: is there a benefit to either approach? Urology. 2006;67(3):466-471.

34. Rodel C, Grabenbauer GG, Kuhn R, et al. Combined-modality treatment and selective organ preservation in invasive bladder cancer: long-term results. J Clin Oncol. 2002;20(14):3061-3071.

35. Shipley WU, Winter KA, Kaufman DS, et al. Phase III trial of neoadjuvant chemotherapy in patients with invasive bladder cancer treated with selective bladder preservation by combined radiation therapy and chemotherapy: initial results of Radiation Therapy Oncology Group 89-03. J Clin Oncol. 1998;16(11):3576-3583.

36. James ND, Hussain SA, Hall E, et al. Radiotherapy with or without chemotherapy in muscle-invasive bladder cancer. $N$ Engl J Med. 2012;366(16):1477-1488.

37. Stenzl A, Cowan NC, De Santis M, et al. Treatment of muscle-invasive and metastatic bladder cancer: update of the EAU guidelines. Eur Urol. 2011;59(6):1009-1018.

38. Neoadjuvant chemotherapy in invasive bladder cancer: update of a systematic review and meta-analysis of individual patient data advanced bladder cancer (ABC) meta-analysis collaboration. Eur Urol. 2005;48(2):202-205; discussion 205-206.

39. von der Maase H, Sengelov L, Roberts JT, et al. Long-term survival results of a randomized trial comparing gemcitabine plus cisplatin, with methotrexate, vinblastine, doxorubicin, plus cisplatin in patients with bladder cancer. J Clin Oncol. 2005;23(21):4602-4608.

40. von der Maase H, Hansen SW, Roberts JT, et al. Gemcitabine and cisplatin versus methotrexate, vinblastine, doxorubicin, and cisplatin in advanced or metastatic bladder cancer: results of a large, randomized, multinational, multicenter, phase III study. J Clin Oncol. 2000;18(17):3068-3077.

41. Adjuvant chemotherapy in invasive bladder cancer: a systematic review and meta-analysis of individual patient data Advanced Bladder Cancer (ABC) Meta-analysis Collaboration. Eur Urol. 2005;48(2):189-199; discussion 199-201.

42. Motzer RJ, Hutson TE, Tomczak P, et al. Overall survival and updated results for sunitinib compared with interferon alfa in patients with metastatic renal cell carcinoma. J Clin Oncol. 2009;27(22): 3584-3590. 
43. Bellmunt J, Gonzalez-Larriba JL, Prior C, et al. Phase II study of sunitinib as first-line treatment of urothelial cancer patients ineligible to receive cisplatin-based chemotherapy: baseline interleukin- 8 and tumor contrast enhancement as potential predictive factors of activity. Ann Oncol. 2011;22(12):2646-2653.

44. Gallagher DJ, Milowsky MI, Gerst SR, et al. Phase II study of sunitinib in patients with metastatic urothelial cancer. J Clin Oncol. 2010;28(8): 1373-1379.

45. Sridhar SS, Winquist E, Eisen A, et al. A phase II trial of sorafenib in first-line metastatic urothelial cancer: a study of the PMH Phase II Consortium. Invest New Drugs. 2011;29(5):1045-1049.

46. Dreicer R, Li H, Stein M, et al. Phase 2 trial of sorafenib in patients with advanced urothelial cancer: a trial of the Eastern Cooperative Oncology Group. Cancer. 2009;115(18):4090-4095.

47. Li Y, Yang X, Su LJ, Flaig TW. Pazopanib synergizes with docetaxel in the treatment of bladder cancer cells. Urology. 2011;78(1):233. e7-e13.

48. Necchi A, Mariani L, Zaffaroni N, et al. Pazopanib in advanced and platinum-resistant urothelial cancer: an open-label, single group, phase 2 trial. Lancet Oncol. 2012;13(8):810-816.

49. Lamont FR, Tomlinson DC, Cooper PA, Shnyder SD, Chester JD, Knowles MA. Small molecule FGF receptor inhibitors block FGFRdependent urothelial carcinoma growth in vitro and in vivo. Br J Cancer. 2011;104(1):75-82.

50. Hahn NM, Stadler WM, Zon RT, et al. Phase II trial of cisplatin, gemcitabine, and bevacizumab as first-line therapy for metastatic urothelial carcinoma: Hoosier Oncology Group GU 04-75. J Clin Oncol. 2011;29(12):1525-1530.

51. Twardowski P, Stadler WM, Frankel P, et al. Phase II study of Aflibercept (VEGF-Trap) in patients with recurrent or metastatic urothelial cancer, a California Cancer Consortium Trial. Urology. 2010;76(4):923-926.

52. Lonn U, Lonn S, Friberg S, Nilsson B, Silfversward C, Stenkvist B. Prognostic value of amplification of c-erb-B2 in bladder carcinoma. Clin Cancer Res. 1995;1(10):1189-1194.

53. Jimenez RE, Hussain M, Bianco FJ Jr, et al. Her-2/neu overexpression in muscle-invasive urothelial carcinoma of the bladder: prognostic significance and comparative analysis in primary and metastatic tumors. Clin Cancer Res. 2001;7(8):2440-2447.

54. Wulfing C, Machiels JP, Richel DJ, et al. A single-arm, multicenter, open-label phase 2 study of lapatinib as the second-line treatment of patients with locally advanced or metastatic transitional cell carcinoma. Cancer. 2009;115(13):2881-2890.

55. Salzberg M, Borner M, Bauer JA, Morant R, Rauch D, Rochlitz C. Trastuzumab (Herceptin) in patients with HER-2-overexpressing metastatic or locally advanced transitional cell carcinoma of the bladder: report on 7 patients. Eur J Cancer. 2006;42(15):2660-2661.

56. Peyromaure M, Scotte F, Amsellem-Ouazana D, Vieillefond A, Oudard S, Beuzeboc P. Trastuzumab (Herceptin) in metastatic transitional cell carcinoma of the urinary tract: report on six patients. Eur Urol. 2005;48(5):771-775; discussion 775-778.

57. Hussain MH, MacVicar GR, Petrylak DP, et al. Trastuzumab, paclitaxel, carboplatin, and gemcitabine in advanced human epidermal growth factor receptor-2/neu-positive urothelial carcinoma: results of a multicenter phase II National Cancer Institute trial. J Clin Oncol. 2007;25(16):2218-2224.

58. Cheng J, Huang H, Zhang ZT, et al. Overexpression of epidermal growth factor receptor in urothelium elicits urothelial hyperplasia and promotes bladder tumor growth. Cancer Res. 2002;62(14):4157-4163.

59. Neal DE, Marsh C, Bennett MK, et al. Epidermal-growth-factor receptors in human bladder cancer: comparison of invasive and superficial tumours. Lancet. 1985;1(8425):366-368.

60. Wong YN, Litwin S, Vaughn D, et al. Phase II trial of cetuximab with or without paclitaxel in patients with advanced urothelial tract carcinoma. J Clin Oncol. 2012;30(28):3545-3551.

61. Motzer RJ, Escudier B, Oudard S, et al. Efficacy of everolimus in advanced renal cell carcinoma: a double-blind, randomised, placebocontrolled phase III trial. Lancet. 2008;372(9637):449-456.
62. Tickoo SK, Milowsky MI, Dhar N, et al. Hypoxia-inducible factor and mammalian target of rapamycin pathway markers in urothelial carcinoma of the bladder: possible therapeutic implications. BJU Int. 2011; 107(5):844-849.

63. Mansure JJ, Nassim R, Chevalier S, Rocha J, Scarlata E, Kassouf W. Inhibition of mammalian target of rapamycin as a therapeutic strategy in the management of bladder cancer. Cancer Biol Ther. 2009; 8(24):2339-2347.

64. Seront E, Rottey S, Sautois B, et al. Phase II study of everolimus in patients with locally advanced or metastatic transitional cell carcinoma of the urothelial tract: clinical activity, molecular response, and biomarkers. Ann Oncol. 2012;23(10):2663-2670.

65. Milowsky MI, Regazzi AM, Garcia-Grossman IR, et al. Final results of a phase II study of everolimus (RAD001) in metastatic transitional cell carcinoma (TCC) of the urothelium. J Clin Oncol. 2011;29(Supp1): Abstr 4606.

66. Gerullis H, Eimer C, Ecke TH, et al. A phase II trial of temsirolimus in second-line metastatic urothelial cancer. Med Oncol. 2012;29(4): 2870-2876.

67. Juanpere N, Agell L, Lorenzo M, et al. Mutations in FGFR3 and PIK3CA, singly or combined with RAS and AKT1, are associated with AKT but not with MAPK pathway activation in urothelial bladder cancer. Hum Pathol. 2012;43(10):1573-1582.

68. Courtney KD, Corcoran RB, Engelman JA. The PI3K pathway as drug target in human cancer. J Clin Oncol. 2010;28(6):1075-1083.

69. Molins JB, Werner L, Guix M, et al. PI3KCA mutations in advanced urothelial carcinoma: a potential therapeutic target? 2012;30(Suppl 15): Abstr 4582.

70. Sharma P, Gnjatic S, Jungbluth AA, et al. Frequency of NY-ESO-1 and LAGE-1 expression in bladder cancer and evidence of a new NYESO-1 T-cell epitope in a patient with bladder cancer. Cancer Immun. 2003;3:19.

71. Sharma P, Bajorin DF, Jungbluth AA, Herr H, Old LJ, Gnjatic S. Immune responses detected in urothelial carcinoma patients after vaccination with NY-ESO-1 protein plus BCG and GM-CSF. J Immunother. 2008;31(9):849-857.

72. Zhang P, Wang J, Wang D, et al. Dendritic cell vaccine modified by Ag85A gene enhances anti-tumor immunity against bladder cancer. Int Immunopharmacol. 2012;14(3):252-260.

73. Swana HS, Grossman D, Anthony JN, Weiss RM, Altieri DC. Tumor content of the antiapoptosis molecule survivin and recurrence of bladder cancer. N Engl J Med. 1999;341(6):452-453.

74. Kitamura H, Torigoe T, Honma I, et al. Expression and antigenicity of survivin, an inhibitor of apoptosis family member, in bladder cancer: implications for specific immunotherapy. Urology. 2006;67(5): 955-959.

75. Hirohashi Y, Torigoe T, Maeda A, et al. An HLA-A24-restricted cytotoxic T lymphocyte epitope of a tumor-associated protein, survivin. Clin Cancer Res. 2002;8(6):1731-1739.

76. Honma I, Kitamura H, Torigoe T, et al. Phase I clinical study of antiapoptosis protein survivin-derived peptide vaccination for patients with advanced or recurrent urothelial cancer. Cancer Immunol Immunother. 2009;58(11):1801-1807.

77. Carthon BC, Wolchok JD, Yuan J, et al. Preoperative CTLA-4 blockade: tolerability and immune monitoring in the setting of a presurgical clinical trial. Clin Cancer Res. 2010;16(10):2861-2871.

78. Liakou CI, Kamat A, Tang DN, et al. CTLA-4 blockade increases IFNgamma-producing CD4+ICOShi cells to shift the ratio of effector to regulatory T cells in cancer patients. Proc Natl Acad Sci U S A. 2008;105(39):14987-14992.

79. Hendricksen K, Gleason D, Young JM, et al. Safety and side effects of immediate instillation of apaziquone following transurethral resection in patients with nonmuscle invasive bladder cancer. J Urol. 2008;180(1):116-120.

80. Hendricksen K, Cornel EB, de Reijke TM, Arentsen HC, Chawla S, Witjes JA. Phase 2 study of adjuvant intravesical instillations of apaziquone for high risk nonmuscle invasive bladder cancer. $J$ Urol. 2012;187(4):1195-1199. 
81. Kowalski M, Entwistle J, Cizeau J, et al. A Phase I study of an intravesically administered immunotoxin targeting EpCAM for the treatment of nonmuscle-invasive bladder cancer in BCGrefractory and BCGintolerant patients. Drug Des Devel Ther. 2010;4:313-320.

82. Brunner A, Prelog M, Verdorfer I, Tzankov A, Mikuz G, Ensinger C. EpCAM is predominantly expressed in high grade and advanced stage urothelial carcinoma of the bladder. J Clin Pathol. 2008;61(3):307-310.

83. Kowalski M, Guindon J, Brazas L, et al. A Phase II study of oportuzumab monatox: an immunotoxin therapy for patients with noninvasive urothelial carcinoma in situ previously treated with bacillus Calmette-Guerin. J Urol. 2012;188(5):1712-1718.
84. Ristimaki A, Nieminen O, Saukkonen K, Hotakainen K, Nordling S, Haglund C. Expression of cyclooxygenase-2 in human transitional cell carcinoma of the urinary bladder. Am J Pathol. 2001;158(3): 849-853.

85. Gulec M, Akin H, Yuce $\mathrm{HH}$, et al. Adenosine deaminase and xanthine oxidase activities in bladder washing fluid from patients with bladder cancer: a preliminary study. Clin Biochem. 2003;36(3):193-196.

\section{Publish your work in this journal}

Research and Reports in Urology is an international, peer-reviewed, open access journal publishing original research, reports, editorials, reviews and commentaries on all aspects of adult and pediatric urology in the clinic and laboratory including the following topics: Pathology, pathophysiology of urological disease; Investigation and treatment of

\section{Dovepress}

urological disease; Pharmacology of drugs used for the treatment of urological disease. The manuscript management system is completely online and includes a very quick and fair peer-review system, which is all easy to use. Visit http://www.dovepress.com/testimonials.php to read real quotes from published authors.

Submit your manuscript here: http://www.dovepress.com/research-and-reports-in-urology-journal 